\title{
A IMAGEM DA BRUXA: DA ANTIGUIDADE HISTÓRICA ÀS REPRESENTAÇÕES FÍLMICAS CONTEMPORÂNEAS
}

\author{
Bruno Vinicius Kutelak Dias ${ }^{1^{*}}$ \\ ${ }^{1}$ Universidade Federal do Paraná, Curitiba, Paraná, Brasil \\ Regina Helena Urias Cabreira ${ }^{2 *}$ \\ ${ }^{2}$ Universidade Tecnológica Federal do Paraná, Curitiba, Paraná, Brasil
}

\begin{abstract}
Resumo
Este artigo tem como objetivo ressaltar o desenvolvimento históricosocial da imagem da bruxa de acordo com as perspectivas culturais, sociais e religiosas desde os primórdios de nossa civilização ocidental até a era contemporânea. Este panorama histórico será discutido com base na influência mitológica no que se refere à formação da imagem feminina transgressora que deu origem à renomada "caça às bruxas" na Idade Média. Para tanto, tomaremos como base os escritos de Civita, (1997), Blécourt (2017), Clark (2006), Maxwell-Stuart (2017), Page (2017), Sharpe (2017), Wallis (2017) e de versões fílmicas contemporâneas, desde The Wizard of $O z$ (1939) até The Witch (2015), que retratam a transformação da imagem da bruxa para que possamos analisar, através de sua iconografia, como tal imagem foi e é relegada aos ditames de diversas épocas históricas.

Palavras-chave: Bruxa; Bruxaria; História; Mitologia; Cinema.
\end{abstract}

\section{THE WITCH'S IMAGE: FROM HISTORICAL ANTIQUITY TO CONTEMPORARY FILM REPRESENTATIONS}

\begin{abstract}
This article aims at discussing the historical-social development of the witch's image according to cultural, social and religious perspectives since the earlier stages of our Western civilization until the contemporary era. This historic overview will be discussed according to mythological influences referring to the construction of the female image as transgressor which originated the acclaimed Middle Age "witch hunt". In order to do so, we will use works by Civita, (1997), Blécourt (2017), Clark (2006),
\end{abstract}

\footnotetext{
${ }^{*}$ Doutorando em Estudos Literários pela Universidade Federal do Paraná. Mestre em Estudos Literários pela mesma instituição. Graduado em Letras pela Universidade Tecnológica Federal do Paraná. Seu e-mail é: brunokutelak@gmail.com. ORCID: 0000-0002-7755-8120.

** Pós-doutora pela Universidade Harvard. Doutorado Interdisciplinar em Ciências Humanas pela Universidade Federal de Santa Catarina. Mestrado em Literaturas de Língua Inglesa pela Universidade Federal do Paraná. Professora Titular da Universidade Tecnológica Federal do Paraná. Seu e-mail é: rhcabreira@gmail.com. ORCID: 0000-0002-5918-5631.
} 
Maxwell-Stuart (2017), Page (2017), Sharpe (2017) and Wallis (2017) apart from contemporary film versions from The Wizard of $\mathrm{O} z$ (1939) through The Witch (2015), which depict the witch's image transformation, so we can analyze, through its iconography, how such image was and is determined by the demands of several historical eras.

Keywords: Witch; Witchcraft; History; Mythology; Cinema. 


\section{A bruxaria e o feminino através da história}

Bruxa, feiticeira, mandingueira, adivinha, vidente, maga, mágica, necromante, nigromante, lâmia, xamã, sábia, sacerdotisa, pitonisa são alguns dos termos associados àquela mulher que manifestava e manifesta algum conhecimento sobre - presságios, adivinhações, benzeduras, curas através das ervas, partos e orações - cultuando um mundo invisível, mágico, misterioso e numinoso sobre o qual o conhecimento científico e racional tem muito pouco a explicar e comprovar. Para que entendamos as transformações históricas pelas quais as representações da imagem da "bruxa" passou, se faz necessário olharmos para um passado bem longínquo em que o feminino era visto como força fundamental para a sobrevivência na terra.

Como nos conta a História e nos comprovam estudos arqueológicos ${ }^{1}$ houve uma época em que uma cultura "matrifocal" regia nossa civilização. Tal cultura denomina-se "matrifocal," e não "matriarcal," pelo fato de não permitir, principalmente, distinções hierárquicas entre homens e mulheres. ${ }^{2}$ Não havendo relações baseadas no poder, os indivíduos relacionavam-se com o princípio do coletivo, do trabalho e vida em comunidade onde não havia espaço para guerras, ameaças e destruições de seus semelhantes. A vida era totalmente regida pela relação entre o indivíduo e a natureza. As mulheres, por seus ciclos menstruais e de fertilidade e gestação, eram diretamente relacionadas com os ciclos da natureza. A própria terra era considerada como a "grande mãe," aquela que nutria e dava sustento àqueles que dela dependiam, daí a importância atribuída ao aspecto "feminino," tanto do ser humano quanto da terra que habitava. O indivíduo era totalmente absorvido e integrado à natureza, aos seus ciclos de vida e morte, e aos cuidados ao tratar com a terra, pois dela advinha sua existência e continuidade. ${ }^{3}$ (CABREIRA, 2012, p. 23-24)

Tal cultura matrifocal foi primordialmente retratada através da mitologia, do folclore e de achados arqueológicos, em que foram encontrados não só pinturas rupestres neolíticas em cavernas representando figuras femininas, bem como esculturas do corpo feminino bastante avantajado em tamanho, como a Vênus de Willendorf (CIVITA, 1997, p. 10) com seus seios e corpo arredondados, representando feminilidade e fertilidade: a mulher doadora de vida.

De acordo com a explicação de Joseph Campbell: "Não resta dúvida de que nas épocas mais remotas da história do homem a força mágica e misteriosa da fêmea era tão maravilhosa quanto o próprio universo; e isto atribuiu à mulher um poder prodigioso, poder este que tem sido uma das maiores preocupações da parte masculina da população - como quebrálo, controlá-lo e usá-lo para seus próprios fins." (apud CIVITA, 1997, p. 11)

Os desacordos causados entre o feminino e o masculino, então, seriam retratados nas mitologias de diversas culturas desde a do povo agrário sumério (4.000 a.C.) até as invasões das tribos guerreiras semitas, antigos caçadores, e dos povos da Europa e do sul da Rússia, os invasores helênicos e arianos, criadores 
de gado, que desestruturariam as sociedades harmônicas e não-heróicas, nas quais se manifestava o culto à Deusa. Tais intrusos paulatinamente substituiriam as mitologias baseadas na tradição da Deusa-Mãe por aquelas representadas por divindades masculinas e guerreiras, em figuras como Javé e Zeus. (CIVITA, 1997, p. 13). Consequentemente, as tensões desencadeadas por tais diferenças culminariam numa das mais nefastas turbulências sociais na Europa medieval, a caça às bruxas.

Quando começam as invasões nos domínios da deusa, surge um novo tema recorrente na mitologia: um herói, deus ou mortal, destrói uma corporificação monstruosa de uma deusa que antes fora suprema, e por fim recebe um tesouro fabuloso, que trará benefícios a toda a humanidade. (CIVITA, 1997, p. 15)

Como exemplos desta mudança em relação à figura da Deusa, podemos citar algumas lendas tidas como "revisionistas [...] nas quais a deusa é destruída ou na melhor das hipóteses, casa-se e é relegada a um papel inferior, [imagens estereotipadas que] sobreviveram nas tradições bíblicas do Velho e do Novo Testamento, bem como nos mitos homéricos da Grécia e de Roma" (CIVITA, 1997, p. 15). Assim, temos a lenda babilônica de Marduk e Tiamat; as lendas gregas de Zeus e Tifon; a lenda semita de Lilith; a lenda grega da Medusa, uma das três Górgonas, e a lenda da "arquifeiticeira Hecade, temível rainha do baixomundo" (CIVITA, 1997, p. 19); e a lenda de Circe, a maga loira, que desempenha um papel importante na Odisséia [...] e Homero e sua sobrinha Medéia. Figuras femininas, e muitas vezes animalescas, que representam o lado temido, malévolo, destruidor e sombrio da Deusa-Mãe, que passa de "mãe-doadora" para aquela "mãe-devoradora" que toma a vida de forma vingativa, trágica e avassaladora, conservando a natureza ambivalente de bem e mal que sempre foi a marca da divindade feminina.

Com poucas e notáveis exceções, tais como Afrodite e Atena, as divindades femininas da mitologia homérica viriam a assumir traços e comportamentos sombrios e ameaçadores, delineando o posterior mito europeu da bruxa. Mas esse processo de passagem, do culto a uma deusa que continha tanto a vida como a morte, para um culto no qual o lado sombrio encobria sua luz, transcorreu como um processo gradual e que jamais chegou a um desfecho. Deusas e deuses, seres de um nível mais alto e mais baixo, possuídos pelo bem e pelo mal, continuaram a surgir nas mitologias da Grécia e de Roma. (CIVITA, 1997, p. 16)

Apesar dessa desmistificação da figura da Deusa-Mãe, tanto romanos quanto gregos cultuavam algumas divindades que ainda remetiam às tradições antigas que reverenciavam a magia, cujas celebrações se assemelhariam ao futuro sabá das bruxas. Em Roma temos o culto à deusa-mãe Cibele; na Grécia o culto a Dionísio; os mistérios Eleusínios (considerados os mais dignos) em homenagem a Demeter, deusa da terra e esposa de Zeus; a deusa da lua Diana (Roma) e Artémis (Grécia); e as lendas sobre as strigaes dos antigos povos germânicos do norte da 
Europa, que de acordo com "Festus [eram] "mulheres que praticam feitiçaria e que são chamadas de mulheres voadoras"' (CIVITA, 1997, p. 23).

Mas na Roma antiga havia uma alta distinção entre magia branca e negra, sendo que a última era punida com a morte, principalmente se colocasse o estado e o imperador em risco. Assim, até a queda do Império Romano, temos a figura do(a) bruxo(a) que designava aquele(a) que praticava a magia - uma atividade corriqueira - e havia feiticeiros(as) em quase todas as comunidades. Contudo, por possuir um poder dual tanto para o bem quanto para o mal, o praticante de magia ou feitiçaria era temido por sua capacidade de proporcionar a ruína de uma pessoa, de uma plantação, de um rebanho ou desencadear intempéries seja por vingança ou desafeto. Assim, por precaução, procurava-se não desencadear a ira num mago. (CIVITA, 1997, p. 25).

Outro fato que se faz relevante é a associação de tais figuras mágicas com incursões e festas noturnas, ideias que mais tarde seriam relacionadas aos encontros entre Satã e as bruxas. Pois, "nas terras do norte as reuniões de feiticeiras eram conduzidas pela deusa Holda, esposa de Wotan" (CIVITA, 1997, p. 27), que representava tanto fertilidade quanto destruição "com seus exércitos de Valquírias"; além da temerária Freyja, a "senhora dos mortos".

Além das divindades germânicas e nórdicas temos também as deusas da mitologia celta que eram relacionadas com as guerras e com a arte do combate, tais figuras se mesclavam à variedade de demônios, ninfas e elfos do folclore britânico. Com relação àquela cultura, faz-se importante enfatizar que os celtas acreditavam no poder da magia e em sua eficácia e incorporavam tal poder em suas práticas sociais, contudo também não toleravam o uso da magia para fins malévolos, assim como os romanos.

Para que possamos analisar a dimensão dessa atitude de aceitação da magia e da feitiçaria, além de sua transformação através dos tempos, se faz necessário considerar que

Na Europa predominava uma visão mágica do mundo, tanto entre pagãos como entre os cristãos. As mensagens da mitologia e do folclore não estavam apenas nas profundezas da psique humana; possuíam um significado real e imediato. Também traduziam um equilíbrio delicado entre amor e ódio pela bruxa, figura de poder aparentemente imenso. E esse equilíbrio, ao que parece, sempre parecia prestes a pender para o lado do medo e do horror. As pessoas pensavam saber o que era uma feiticeira; na verdade, conheciam-na por mais de uma dúzia de nomes diferentes. Precisavam apenas de mais um pretexto para dar vazão a seus instintos e atacar a fonte de inquietude que a bruxa representava. Infelizmente, isso foi exatamente o que ocorreu quando o cristianismo reivindicou seus direitos de gerir tanto suas vidas quanto suas lealdades. (CIVITA, 1997, p. 30)

Assim, desde os primórdios das civilizações observamos que a figura feminina foi, e tem sido, retratada de acordo com conceitos e pré-conceitos muitas vezes discrepantes, oriundos de aspectos culturais, sociais, políticos, psicológicos e religiosos que distorcem as características das mulheres enquanto 
seres individuais e sociais. Fato que se impõe diretamente ao poder de ação e reação que a mulher possa ter dentro de seu contexto histórico-cultural.

Relatos que enfatizam como, historicamente, as transgressões aos valores das sociedades em que algumas mulheres viveram as colocaram à mercê de fatores que determinaram seus destinos de forma trágica. Como nos exemplos de Margarida Porete e Joana D'Arc, ${ }^{4}$ estas mulheres foram condenadas por sustentarem comportamentos e ideais transgressores que as denegriram e levaram à condenação por "bruxaria", demonstrando intolerância e rigidez para com aspectos divergentes na atuação feminina em sociedade.

Como nos relata Rose Marie Muraro, em sua "Breve Introdução Histórica" da edição brasileira da obra Malleus Maleficarum: O Martelo das Feiticeiras (2002), "é preciso termos uma visão ao menos mínima da História da mulher no interior da História humana," se quisermos avaliar as condições que relegaram a mulher ao obscurecimento, à perseguição e "castração" psicológica e moral em algumas épocas. Muraro faz uma retrospectiva histórica desde as primeiras culturas de coleta e de caça em que a força física não era necessária para a sobrevivência e em que as mulheres possuíam um lugar central e eram consideradas como seres sagrados, integralmente ligadas à natureza -, até que a mulher se torne um ser subjugado pelas sociedades patriarcais. (CABREIRA, 2012, p. 221)

Assim como declara Katherine Howe, quando pensamos a respeito de bruxas nos dias de hoje, um padrão de imagem aparece em nossas mentes: uma velha com nariz enverrugado, chapéu pontudo preto, trapos como roupas e um gato preto a seu lado $(2014$, p. 3), além da relação quase que estrita com a maldade, o obscuro e o Diabo. No entanto, com o passar do tempo, tal imagem vem sendo apresentada sob diversas outras perspectivas, tanto quando consideramos a literatura quanto o cinema. Da tradicional feiticeira assustadora que adquire seus poderes em conluio com o Demônio até crianças que usam seus poderes natos na luta contra forças maléficas, as bruxas povoam a imaginação da sociedade desde seus primórdios. Nosso objetivo principal neste artigo é analisar como o imaginário envolvendo a figura da bruxa aparece nas personagens de obras cinematográficas e como elas se relacionam com as tradições que envolvem a magia e sua história.

Rotulada como demoníaca, a magia percorre um longo caminho desde as sociedades mais antigas. Desde povos que possuíam como divindade superior a Grande Mãe, como já mencionado, até as práticas modernas de bruxaria, wicca e religiões com bases esotéricas, o comportamento mágico sempre esteve presente, desde rituais extremamente elaborados até simpatias simples, passadas de geração em geração como forma de proteção ou solução rápida para algum problema. As mais diversas culturas apresentam alguma forma de ritual mágico, desde orações, conjuração de nomes e palavras mágicas, amuletos até bonecos utilizados para infligir dor em alguma pessoa por meio de agulhas espetadas; vale notar a presença desse último objeto não apenas em culturas africanas popularmente conhecidas pela prática de rituais como o voodoo, mas também em 
diversas culturas, entre elas o Judaismo (MAXWELL-STUART in DAVIS, 2017, p. 15). Tanto benevolente quanto hostil, a magia estava a serviço da sociedade para os mais diversos propósitos. O problema da magia não se deve estritamente à sua natureza sobrenatural, mas sim ao que foge do ritual sagrado oficial:

In the early Middle Ages people used and feared magic for the same reason they used and feared any other sacred ritual: magic was thought to strengthen or sever relationships between people, to overcome material obstacles, and to spread good or evil by protecting a community or introducing sickness and death. But magic was the name given to a class of inappropriate sacred rituals, which were excluded from normative Christian practice. [...] An unauthorized sacred ritual was thought to express its practitioner's ignorance of appropriate sacred forms, adherence to heathen practice, or association with the Devil. (PAGE in DAVIS, 2017, p. 29)

O "triunfo" do Cristianismo sobre o Paganismo lhe dá aparente imagem de superioridade divina sobre os demais poderes demoníacos associados à feitiçaria, já que, na Idade Média, os magos eram comumente tidos como o contraponto dos santos: a apropriação de determinados poderes sobrenaturais de forma positiva, relacionados aos magos, como o controle dos elementos da natureza e a cura, davam aos santos a posição benevolente considerando Deus como a origem de tais poderes miraculosos; em oposição, a magia prática, divinação ou qualquer outro ato fora do alcance da Igreja era considerado como atividade demoníaca (PAGE in DAVIS, 2017, p. 29-30). Os costumes advindos do paganismo ${ }^{5}$ poderiam ter sido absorvidos pelo Cristianismo; no entanto, a seus praticantes restava a perseguição.

Nesse ponto a magia passa a ser quase que indissociável da imagem de Satã. Sob a visão da Igreja Medieval, os hereges praticantes de bruxaria funcionavam como meios para que o Príncipe das Trevas pudesse atuar no mundo físico. Seus escolhidos, como já mencionado, estavam destinados à perdição e abandonavam a verdadeira fé, que seria no Deus cristão, para se render às tentações do Diabo. A partir daqui, um fato de extrema importância serve como divisor de águas quando nos referimos à bruxaria: a associação quase que integral da magia ao sexo feminino. Embora não existisse tal relação tão estrita previamente e nem grandes demonstrações de ódio às mulheres (CLARK, 2006), elas passam a ser vistas como as preferidas de Satanás para a realização de seus atos contra Deus e a humanidade. Segundo Clark (2006), mesmo de forma pouco elaborada, as proposições a respeito dessa relação entre mulher e Demônio se dividiam em, basicamente, três grupos expressos de maneira quase metódica:

Primeiro, supunha-se, como princípio geral, que as mulheres eram, por natureza, mais fracas que os homens com respeito a qualidades intelectuais e psicológicas fundamentais e, portanto, tinham o que o autor chamou de "maior facilidade para a queda". Segundo o Malleus maleficarum elas não poderiam aprender adequadamente assuntos espirituais e eram crédulas e impressionáveis em suas crenças. Ao mesmo tempo, suas "paixões e afeições descontroladas" deixavam-nas ressentidas com a autoridade 
e difíceis de disciplinar, de forma que eram uma ameaça potencial permanente à ordem de Deus. A chave para sua perversidade residia, sobretudo, em seus apetites carnais, que eram muito maiores que os dos homens. As mulheres eram, pois, mentalmente fracas e de comportamento instável, criaturas imperfeitas por natureza, de quem só se poderia esperar o mal e a depravação. ${ }^{6}$ (CLARK, 2006, p. 163)

O rebaixamento da mulher a uma posição quase que infantilizada intelectual e psicologicamente é um dos primeiros pontos a serem observados quanto à sua associação com a bruxaria. Não ser capaz de discernir adequadamente entre o bem e o mal as coloca em lugar propício para a influência negativa por parte dos demônios, vindo a cair em suas garras por falta da inteligência que seria mais avantajada nos homens. Ponto interessante que diz respeito a essa suposta debilidade intelectual reaparece quando a bruxaria sobrenatural começa a ser desmentida, talvez em um princípio de racionalização sobre o tema; segundo Sharpe (in DAVIS, 2017) declarou-se que aqueles que renunciassem a Cristo ou fizessem um pacto com o Diabo deveriam ser punidos como apóstatas ou idólatras, "but much of what witches were supposed to do was either illusory or based on faulty intellectual premises" (p. 79). Em segundo lugar, as mulheres seriam mais carnais do que os homens; como observamos anteriormente, características associadas aos instintos eram relegadas ao sexo feminino, já que aos homens cabia o lado racional mais desenvolvido, e com isso vem a ideia de que sexo, ambição e inconstância eram aspectos muito mais próximos do feminino do que do masculino, traços esses também relacionados com o Demônio e nisso se funda o argumento principal do Malleus maleficarum: "all witchcraft comes from carnal lust, which is in women insatiable. [...] Wherefore for the sake of fulfilling their lusts they consort even with devils" (Malleus maleficarum, Parte 1, Questão 7). Assunto recorrentemente apontado pelos autores sobre bruxaria dessa época é a sedução de Eva pelo Diabo, a primeira pecadora que, por sua vez, seduziu Adão para que desobedecesse as ordens de Deus. "Alguns chegaram a chamar Eva de a primeira bruxa, uma associação que, mais do que qualquer outra, torna inteligível o vínculo de gênero sobre o qual todos se apoiavam" (CLARK, 2006, p. 164). Porém, a bruxaria ainda exigia mais vínculos com o sexo feminino:

O terceiro elemento no argumento era explicar quaisquer outras características específicas do crime em termos de fraquezas e deficiências características femininas. Por exemplo, as mulheres eram igualmente curiosas e loquazes - "linguarudas" [...] Isto as tornava mais ávidas que os homens por saber coisas proibidas, mas menos capazes de conserválas para si. Além disso, eram mentirosas, orgulhosas, fúteis e cobiçosas, fraquezas que o diabo poderia explorar nos estágios iniciais de sua campanha para prendê-las. [...]

Mais do que qualquer outra coisa, as mulheres eram maliciosas, rancorosas e vingativas $[\ldots]$

Mesmo um leve desgosto [...] poderia impelir as mulheres para o diabo, isto trabalhava em seu favor, assim como a satisfação de seu orgulho e de sua avidez pelo mando. (CLARK, 2006, p. 164) 
Curiosidade, fraqueza, mentira, orgulho, futilidade, malícia, rancor, vingança e as mais reprováveis características humanas eram relacionadas quase que exclusivamente às mulheres, fazendo-as iscas perfeitas para o Diabo e seus servos. Até mesmo uma pseudo-ciência servia de justificativa para que as mulheres fossem colocadas como inferiores, como o formato de seus corpos e suas entranhas. A imagem da bruxa é, então, moldada de acordo com tais crenças e abarca não apenas pessoas específicas, mas todo um gênero que dividiria traços semelhantes físicos, comportamentais e intelectuais. Além disso, ainda reforça o demoníaco naquelas que fogem aos padrões de juventude e beleza, como as velhas, mendigas, doentes, as obstinadas e dominadoras, as que usurpavam o controle masculino, as que se comportavam como homens, as que buscavam superioridade sexual, as prostitutas ou qualquer mulher às margens da sociedade que não tivessem a imagem da mulher boa e pia, paciente, silenciosa, domesticada e religiosa (CLARK, 2006, p. 184-185).

O mal toma a frente quanto à imagem da bruxa; crenças e rituais populares praticados tanto por homens quanto mulheres são agora obras do Demônio, independentemente das intenções por trás da magia. Segundo Clark (2006, p. 579), no início da Europa Moderna, grande parte da literatura sobre bruxaria tem como objetivo demonizar quaisquer recursos tradicionais preferidos por pessoas necessitadas, ampliando o termo "bruxaria" para incluir todos os artifícios que seriam obstáculos para a hegemonia do clero.

Não restava nesse contexto religioso qualquer aspecto da magia que pudesse ter algum tipo de aprovação. Tanto bruxas boas quanto malignas seriam apenas duas versões do mesmo mal temido e presente no mundo. Satã era responsável pelos poderes de ambas, não importando a intenção daqueles que recorriam a elas em busca de ajuda. As tradições de curandeirismo e medicina "primitiva" que tinham na natureza suas fontes de conhecimento são condenadas. Os adivinhos, desde que não fossem reconhecidos como os profetas do Senhor, também recebiam a pena por heresia e bruxaria. Os encantadores e todos aqueles que lidavam com os aspectos tidos como sobrenaturais eram automaticamente associados ao Demônio e mereciam as inúmeras formas de penalidades da época (CLARK, 2006, p. 585).

Pode-se alegar que tal tipo de comportamento se restrinja a uma época remota, distante tanto no quesito temporal quanto cultural e comportamental; no entanto, a perseguição de tudo aquilo que foge ao conservadorismo tradicional, principalmente levando em consideração os contextos cristãos europeu e americano, se faz presente até os dias de hoje, não importando o quanto haja cada vez mais a ascensão de elementos religiosos que remontam às antigas práticas tidas como bruxaria. Se levarmos em conta que até tempos recentes vigoravam na Inglaterra ${ }^{7}$ leis que tinham a prática de feitiçaria como crime, não podemos afirmar que haja um grande distanciamento da cultura medieval de caça às bruxas e, provavelmente, a imagem associada a elas não tenha se modificado drasticamente com o passar de todos esses anos. 
Da história para o cinema - perpetuação e modificação da imagem da bruxa

Tantas representações e conceitos a respeito das bruxas acabam chegando até os dias de hoje sob diferentes formas. O cinema, por exemplo, é um dos responsáveis por essa disseminação de imagens e funciona tanto como perpetuador quanto modificador da relação que podemos ter com a bruxaria. Se a magia se faz presente desde os primórdios dessa arte, como nos filmes de Méliès, nos quais, curiosamente, ela tinha grande relação com o Diabo, ${ }^{8}$ a bruxa toma seu lugar como personagem icônico em produções cinematográficas desde a temida Bruxa Malvada do Oeste e a doce Glinda, em The Wizard of Oz (1939), ate Thomasin, no mais recente The Witch: a New-England folktale (2015). Uma análise pormenorizada de todas as personagens que já foram denominadas bruxas nesse período de tempo demandaria uma extensão de trabalho muito maior; portanto, vamos nos deter em personagens selecionadas que demonstrem a modificação ou a persistência de um padrão na caracterização e na visão a respeito da feiticeira.

Iniciando pelo clássico The Wizard of $\mathrm{O} z$, acompanhamos Dorothy (Judy Garland) desde sua fazenda no Kansas até a mágica terra de Oz, para onde é levada por um tornado e acidentalmente matando a Bruxa Malvada do Leste. Aterrissando na terra dos Munchkins, Dorothy é recebida por Glinda (Billie Burke), a Bruxa Boa do Norte, chamada para investigar a menina. Glinda é calma, doce e se veste em tons de rosa, com uma coroa e uma varinha de condão. Tal imagem inegavelmente evoca a pureza e bondade raramente associadas às bruxas. Seu contraponto é a Bruxa do Oeste (Margaret Hamilton), cuja aparência evoca o grotesco e o mal, assim como a descrição mencionada previamente dada por Katherine Howe: ela se veste inteiramente de preto, com um chapéu pontudo, sua pele é verde, seu queixo e nariz são desproporcionais, alongando seu rosto de forma caricata. Além disso, a bruxa voa em sua vassoura e se transporta em meio a nuvens de fumaça e fogo, assustando a todos ao redor a ponto de que desmaiem.

As bruxas do Norte e do Oeste formam dois lados de uma figura que, com o passar do tempo, abandona qualquer traço de bondade quando é excluída da sociedade para pertencer ao lado maligno sobrenatural. Embora não haja referências explícitas à religiosidade que relaciona a bruxaria diretamente com o aspecto demoníaco, The Wizard of $\mathrm{O} z$ nos mostra a cultura que distingue entre bondade e maldade pela aparência dada ao indivíduo, como notamos no diálogo entre Glinda e Dorothy:

Glinda: The Munchkins called me because a new witch has just dropped a house on the Wicked Witch of the East. There's the house, and here you are, and that's all that's left of the Wicked Witch of the East.

And so, what the Munchkins want to know is, are you a good witch or a bad witch?

Dorothy: But I've already told you, I am not a witch at all. Witches are old and ugly. 
What was that?

Glinda: The Munchkins. They are laughing because I am a witch. I'm Glinda, the witch of the North.

Dorothy: You are? I beg your pardon. But I've never heard of a beautiful witch before.

Glinda: Only bad witches are ugly.

Se no passado bastava uma imagem física que fugisse aos padrões de beleza e juventude aceitáveis para que uma mulher fosse tachada de bruxa, $\mathrm{Oz}$ reforça um estigma que persiste na sociedade. Dorothy se espanta ao ser indagada sobre ser uma bruxa, alegando o contrário já que bruxas são velhas e feias. Para sua surpresa, Glinda é uma delas, causando a consternação na criança que nunca tinha ouvido falar em uma bruxa bonita antes. A Bruxa do Norte apenas enfatiza que apenas as bruxas más são feias. The Wizard of $\mathrm{O} z$ retrata dois lados da magia, separando-os tanto pelas intenções da feiticeira quanto pela aparência carregada de características até hoje associadas a essa dualidade:

The film obviously contributed to twentieth-century witch imagery. The Wicked Witch bestowed her green face on subsequent witches, especially Halloween representations [...] In contrast, Halloween witches dressed up as Glinda are as rare as they are in films or television series (or are unrecognizable, because they are mistaken for fairies or princesses). (BLÉCOURT in DAVIS, 2017, p. 261)

Mesmo que a bruxa já tenha, antes de $\mathrm{O} z$, uma imagem relacionada com a maldade e com a feiura, provavelmente é a partir dele que esse estereótipo tão tradicional - roupas pretas, chapéu e rosto desfigurado - toma forma no imaginário popular e se torna um ícone de fantasias de Halloween e desenhos animados. Desde então, um estigma já previamente carregado acaba por se tornar padrão, causando estranhamento quando é quebrado, como é o caso do filme I married a witch (1942), estreado pouco tempo depois de The Wizard of $O z$. Neste filme, Jennifer (Veronica Lake) e seu pai ressurgem da morte séculos depois de serem condenados à fogueira pelos colonos da Nova Inglaterra. Desde o trailer do filme, já podemos observar uma quebra com, pelo menos, o aspecto físico grotesco da bruxa, quando o narrador declara: "Now, this little witch was no ordinary witch. Oh, no, she was beautiful". Com isso, nos deparamos com outro aspecto relacionado feminino e responsável pela condenação de quase todo o gênero à relação com o mal: a sedução e a sexualidade.

Jennifer fugia do arquétipo tradicionalmente associado à bruxa; ela era jovem e bonita. No entanto, justamente sua beleza e como ela é retratada pelo filme é que a tornam um perigo para Wallace Wooley, político comprometido com um relacionamento amoroso problemático, o descendente de Jonathan Wooley, o responsável pelas denúncias à Inquisição no século XVII. A bruxa e seu pai renascem na América moderna sob a forma de duas colunas de fumaça. Como o fogo foi responsável pela destruição de seus antigos corpos, por meio da magia Jennifer consegue recobrar sua forma física em meio a um incêndio 
proposital iniciado pelos dois no Hotel Pilgrim, escolhido como parte de seus planos de vingança, já que incendiar o campo de milho não foi possível devido à sua substituição por residências no mundo atual. Wallace e Jennifer se conhecem nesse incêndio, enquanto ele pensa que a está salvando das chamas. Ele a veste, pois estava nua, e a leva para outro quarto, iniciando o plano dela de fazê-lo se apaixonar. Jennifer é sedutora, tentando usar de todos os recursos para conseguir realizar seu desejo de causar sofrimento, como seu tom de fala e seu corpo:

Wallace Wooley: Now you listen to me, young lady. Come on. Get up. Jennifer : I'm listening, Mr. Wooley.

Jennifer: Why do you look at me that way? Oh, my dress. Do you like it? Wallace Wooley: I-I don't know. It's such a shock to see you dressed. I mean... you're beautiful.

Jennifer: Enough to make a man fall in love?

Wallace Wooley: Mere physical beauty isn't everything.

Jennifer : [disappointed] That's what I thought.

Parte dessa sedução se deve a sua praga jogada nos ancestrais de Wallace, a de que jamais se casariam com a mulher ideal, mergulhando os homens da família em um eterno ciclo de casamentos perturbados e infelizes; se conseguisse que ele se apaixonasse, estaria apenas dando continuidade à maldição. Como já observado, uma das premissas do envolvimento do feminino com o diabo era, justamente, sua incessável luxuria e desejo carnal. Além disso, tal tipo de bruxaria era extremamente comum entre as crenças envolvendo as feiticeiras. Clark (2006) afirma que era amplamente aceito que as bruxas pudessem destruir a hierarquia marital semeando a discórdia e incitando a promiscuidade; também provocavam brigas, ciúmes, desentendimentos e disputas, resultado de a magia feminina ser relacionada com a sexualidade e com os sentimentos (p. 131). A imagem da bruxa, nesse caso, pode até se distanciar do horror visual da Bruxa Malvada do Oeste; no entanto, carrega consigo o outro lado condenado, a incitação ao sexo pecaminoso e à destruição da família.

Embora os feiticeiros tenham um comportamento diabólico, como causando incêndios, colocando maldições e a tentativa de arruinar a vida de Wallace fazendo-o se apaixonar por Jennifer, suas imagens não evocam o medo e a repulsa, mas são extremamente cômicas. Ambos possuem discursos caricatos, foram condenados à fogueira por terem feito as ovelhas da vila dançarem e terem mudado as cores das vacas para azul e rosa; enquanto ainda sob a forma de fumaça, depois de ressuscitarem, protagonizam cenas que se desenvolvem beirando o absurdo, chegando a se alojarem dentro de duas garrafas como os mitológicos gênios, plano perfeito para se disfarçarem caso uma delas não tivesse bebida alcoólica, fazendo o pai ficar bêbado. Jennifer é divertida e engraçada até mesmo quando planeja alguma maldade, conseguindo seu objetivo com Wallace enquanto ela mesma se apaixona, formando um casal inesperado. Assim como Glinda, Jennifer é uma nova formulação para a imagem da bruxa. Glinda é boa e pura; Jennifer inicia o filme como má, mas sob uma forma bela e extremamente 
cativante, abrindo o caminho para as bruxas queridas pelo público como Gillian (Kim Novak) do filme Bell, book and candle (1958), a bruxa que mora em um apartamento de Nova York e se apaixona por um publicitário, além de Samantha (Elizabeth Montgomery) e Endora (Agnes Moorehead), as feiticeiras inseridas no mundo moderno do seriado Bewitched (1964-1972).

Entretanto, essa recorrência de amenizar o peso dado à bruxa, tornando-a mais palatável e agradável ao público, logo é quebrada com, no caso, um casal dos mais icônicos do cinema de terror, Minnie e Roman Castevet (Ruth Gordon e Sidney Blackmer) de Rosemary’s baby (1968). O adorável casal se torna amigo dos novos vizinhos, Guy e Rosemary Woodhouse (John Cassavetes e Mia Farrow). Suas aparências queridas e prestativas escondem, pelo menos de Rosemary, sua relação direta com o Demônio, como seus adoradores, chegando a convencer Guy a oferecer sua esposa como receptáculo para o terrível bebê que viria ao mundo por meio de um ritual macabro envolvendo sexo com a própria entidade maligna, tudo isso em troca de fama e sucesso para o aspirante a ator. A história se desenrola com a histeria e pânico de Rosemary fundados em suas desconfianças a respeito da criança que carrega em seu ventre, até que após o nascimento ela aparentemente se rende ao grupo satânico que idolatra seu filho.

Esse filme não apenas retrata um grupo de adoradores de Satã, mas retoma um dos pontos principais da história da bruxa, sua relação estrita com o Diabo e a dependência mútua entre eles, já que, como vimos anteriormente, o Senhor das Trevas dependeria de seus servos, as bruxas e feiticeiros, para poder atuar no mundo físico. Ao contrário da concepção divina de Maria, Satanás não pode escolher a seu bel prazer qualquer mulher e fecundá-la; ele depende do ritual preparado pelos bruxos seguidores dos Castevet e uma mulher que nem mesmo tivesse noção do que estava acontecendo com ela, talvez por puro sadismo e maldade.

Apesar de todo o terror presente no filme, um dos pontos mais marcantes é quando Rosemary começa a ler o livro deixado por seu amigo antes de falecer, como forma de alertá-la a respeito de seus vizinhos. All of them witches trata das bruxas e bruxos famosos e seus rituais, de onde se destaca Adrian Marcato, pai de Steven Marcato, anagrama de Roman Castevet, causando a revolta de Rosemary e despertando pânico por seu bebê:

Guy: With a father like that no wonder he switched his name.

Rosemary: You don't think he is the same...

Guy: What? A witch? Oh, Ro, you're kidding, oh, Ro, honey.

Rosemary: His father was a martyr, do you know how he died?

Guy: Honey, it's 1966...

Rosemary: And this was published in 1933, there were covens in Europe, that's what they are called the... ah... the congregations. Covens in Europe, in America and in Australia and they have one right here, that whole bunch. The parties with the singing and the flute and the chanting, those are sabaths...

Guy: Honey, don't get excited...

Rosemary: Read what they do, Guy! They use blood in their rituals! And the blood that has the most power is baby's blood, and they don't just use the blood, they use the flesh! 
Embora o desejo dos Castevets pelo bebê de Rosemary não seja tão grotesco, a imagem pregada a respeito da bruxa e de supostos rituais feitos nos covens apavora e causa um extremo desconforto no espectador ao acompanhar o drama da pobre mãe encurralada em seu apartamento. Adrian Marcato e as bruxas do livro retratam não apenas o poder demoníaco ligado à bruxaria, mas, principalmente, a perseguição de uma sociedade que busca proteger-se de tais forças, tal qual o povo medieval sob o controle da Igreja. Adrian foi linchado por uma multidão, certamente um fim trágico; no entanto, essa violência perde lugar ao ser comparada com a destruição de vidas inocentes pelas mãos das bruxas satanistas. Enquanto Samantha cativa o público em seu seriado, seguindo os passos de Jennifer, Minnie Castevet aparece como uma má recordação que traz à tona medos que poderiam estar sendo enterrados.

A representação da bruxa não se modifica de forma drástica com o passar dos anos. Mesmo com filmes como The witches of Eastwick (1987) e Elvira: Mistress of the dark (1988) que têm como personagens principais bruxas extremamente cativantes para o espectador, principalmente Elvira (Cassandra Peterson), que se torna um dos ícones do cinema que segue essa temática, a bruxa ainda tem grande associação com o Diabo. Em Eastwick, ele próprio aparece na cidade após ser invocado inocentemente por três mulheres comuns, Alexandra, Jane e Sukie (Cher, Susan Sarondon e Michelle Pfeiffer); pelo menos, as figuras deixam de ser assustadoras e deformadas para continuar dando espaço à beleza feminina. Beleza que acaba exacerbada na sexualidade de Elvira. Além das roupas e acessórios que evocam símbolos relacionados às trevas, como o vestido preto tradicional da bruxa, aranhas, espinhos, caveiras, uma linguagem pouco convencional e o fato de ser apresentadora de filmes de terror, Elvira carrega, principalmente, a luxúria e sexualidade sempre tidas como pecaminosas e responsáveis pela taxação do feminino como impuro e menor em comparação aos homens, que não teriam tais características.

Elvira: Mistress of the dark cria uma bruxa que, embora chame a atenção por sua aparência, traz consigo um conjunto de aspectos, talvez a que mais apresente dentre todas até esse ponto, relativos à bruxaria. Começando por sua presença em uma sociedade que a exclui, fazendo-a permanecer à margem por julgaremna inapropriada para o local. Elvira vai até Massachusetts em busca de sua herança deixada por sua tia Morgana e se depara com um povo extremamente conservador que a reprime de imediato:

Chastity: Listen, young lady, I don't know who you are or where you came from. But you most certainly don't fit in this town. Well, you don't even fit in that dress.

Elvira: Listen, sister. If I want your opinion, I'll beat it out of you.

Chastity: Anita! Anita! She is the Antichrist, I tell you. She is the Antichrist!

Fato interessante no diálogo entre as duas é Elvira ter sido chamada de Anticristo. Segundo Clark (2006), era parte da crença sobre as bruxas a imagem do Anticristo como pertencente a esse grupo. Mencionando o discurso de John Gasule, Clark 
destaca o trecho: "Cristo é um Deus encarnado, a Bruxa é (por assim dizer) um Diabo encarnado. Não digo que uma Bruxa é o Anticristo, mas estou certo de que o Anticristo tem necessidade de ser uma Bruxa" (p. 430). Elvira é tudo o que vai contra a moral conservadora, o Anticristo que vem para destruir os moldes perfeitos da localidade, atraindo os jovens que buscam mais liberdade e diversão, os homens que não podem desviar os olhares e provocando a fúria dos mais velhos e antiquados. É uma mulher livre, tanto no contexto social quanto com relação ao seu corpo; é bruxa não, a princípio, por ter poderes mágicos, que só são descobertos com o decorrer do filme, mas sim por não se adequar aos padrões esperados para uma mulher; é, como já descrito, linguaruda, maliciosa, e, como descrita por Chastity, "a person of easy virtue, a purveyor of pulchritude, one woman Sodom and Gomorrah, if you will, a slimy slithering succubus, a concubine, a streetwalker, a tramp, a slut, a cheap whore". Porém, apesar de tudo isso, Elvira representa, mais uma vez, a bruxa boa, descendente de bruxas que tentavam proteger os poderes da magia das forças do mal, representadas por seu tio, um bruxo satânico. A magia deixa de ser exclusiva do Demônio e passa a ser universal, seu uso tanto para o bem quanto para o mal depende da índole do feiticeiro. Também, talvez um dos fatos mais importantes quando consideramos a personagem é que, mesmo com todos os símbolos e ideias associadas a Elvira, a maldade é representada por um homem, seu tio, não mais pela bruxa mulher.

O que podemos depreender, até agora, é a recorrência da comicidade para retratar o lado bom das bruxas. Talvez como forma de distanciá-las da atmosfera de terror, a comédia sirva como estilo preferido para essa representação. Jennifer, Samantha, Endora, Alexandra, Jane, Sukie e Elvira fazem o público rir como forma de aproximação e aceitação da bruxa, mais uma vez, como parte da sociedade.

A partir dos anos 90, a bruxa parece surgir com mais frequência nas produções tanto do cinema quanto da TV. Já nos primeiros anos temos The witches (1990) e Hocus Pocus (1993), dois filmes inicialmente destinados ao público infanto-juvenil mas que se tornaram clássicos do gênero da fantasia. Em ambos temos, outra vez, o retorno da bruxa demoníaca, principalmente no primeiro, no qual Sra. Ernst (Anjelica Huston), a Grande Bruxa, comanda todas as feiticeiras com o objetivo principal de matar todas as crianças da Inglaterra. Cheias de verrugas, com os pés deformados, carecas e, no caso da Grande Bruxa, uma forma física que mais se assemelha a demônios do que a humanos, elas retomam o legado da Bruxa do Oeste e dos bruxos descritos no livro dado a Rosemary, tanto pela terrível aparência caricata da primeira quanto pelo nível de maldade e sacrifício inocente dos segundos.

O mesmo legado é seguido pelas irmãs Sanderson, de Hocus Pocus. Embora em um filme extremamente mais leve, por se tratar de uma comédia, Winnie, Sarah e Mary (Bette Midler, Sarah Jessica Parker e Kathy Najimi) são retratadas como as bruxas adoradoras de Satã, seu mestre, como afirmam em diversas passagens do filme, chegando a confundi-lo com um dos habitantes da cidade fantasiado para o Halloween. As irmãs são necromantes, um dos mais famosos tipos de magia, conhecido desde a antiguidade pelos oráculos que se 
comunicavam com os mortos. No caso delas, a necromancia está presente em seus objetos mágicos, como o livro feito de pele humana e a vela de sebo de defunto que as trouxe de volta à vida quando acesa na véspera do Dia das Bruxas. Assim como as feiticeiras de The witches, as irmãs Sanderson caçam crianças, no caso, para manter sua juventude e beleza, resultando na mais icônica cena do filme no qual Sarah canta enquanto voa em sua vassoura para enfeitiçar e atrair as crianças de toda a cidade, tal qual Winnie que hipnotiza os adultos que frequentavam a festa de Halloween, com a música I put a spell on you. Se a música e a dança já chegaram a ser consideradas como obras do adversário (WHITMONT, 1993, p. 103), não é de se estranhar sua utilização pelas bruxas em seus rituais, do mesmo modo que Gillian e os Castevet o fazem em seus filmes.

Algum tempo depois, são lançadas, quase que simultaneamente, Sabrina, the teenage witch (1996), The Craft (1996) e Buffy, the vampire slayer (1997), produções que se destinam ao público adolescente e tentam remodelar a figura da bruxa já tão fortemente enraizada no imaginário popular. Sabrina reapresenta uma versão modernizada e jovem de Bewitched, uma nova personagem que seja cativante para o público que não teve contato com Samantha e vinha sendo caçado pelas versões demoníacas das feiticeiras anteriores. Por outro lado, as adolescentes que formam seu próprio coven em The Craft e Willow (Alysson Hannigan), a bruxa de Buffy, reconstroem a imagem da bruxa a partir das novas correntes exotéricas e da grande expansão da Wicca que ocorrem desde a década de 80. Tais novas formas de abordar a magia advêm do constante aumento da busca por uma conexão com uma ancestralidade tanto no âmbito religioso do paganismo quanto em seu estilo de vida, envolvendo diversas culturas como a druídica, nórdica e xamânica (WALLIS in DAVIS, 2017, p. 244-245). As personagens se moldam à sociedade que procura novas crenças e desenvolve uma nova forma de pensamento mágico por meio de experiências como ocorrem em The Craft e Buffy: "the once-non-magician begins to do what magicians do, and begins to find magical ideas persuasive because he begins to notice and respond to events in different ways" (WALLIS in DAVIS, 2017, p. 244). A magia deixa de ser um reduto demoníaco, se insere na sociedade pela experimentação e por sua busca direta. Do mesmo modo, a ideia do mal como aspecto intrínseco da bruxa é transferida para uma característica do ser humano, livrando as bruxas de um peso que carregam desde suas primeiras condenações. Ao contrário do que afirmava, ${ }^{9}$ agora vemos a representação das bruxas boas e más como opostas, tanto no cinema quanto na sociedade, colocando a responsabilidade do uso da feitiçaria naqueles que a buscam, como é visto no filme e no seriado, não em uma força maior que controle a todos como seus servos.

O mesmo padrão de crença se observa no discurso de Sally (Sandra Bullock) do filme Practical Magic (1998), a bruxa dona de uma loja de produtos e medicamentos naturais que está sendo investigada pela polícia devido à morte do namorado de sua irmã: 
Sally: Belladonna, it's a sedative, people put it in their tea to relax, calm their nerves.

Gary: Some people also use it as a poison.

Sally: Which people?

Gary: Witch people.

Sally: Ha...

Gary: Witches.

Sally: Witches... I guess you found me out, huh. You should come around here on Halloween, you'd really see something then.

Gary: Ah, yeah?

Sally: Yeah, we all jump off the roof and fly. We kill our husbands too. Or is that outside your jurisdiction?

Gary: Do you have any idea of how strange this all sounds to me? I got people telling me that you are up here cooking up placenta, that you are into Devil worship...

Sally: No, no, there's no Devil in the craft.

Gary: So, what kind of craft do you do?

Sally: I manufacture bath oils, and soaps, and hand lotions, and shampoo, and the aunts they like to meddle in people's love lifes... Magic isn't just spells and potions. Your badge... it's just a star, just another symbol, your talisman. It can't stop criminals in their tracks, can it? It has power because you believe it does.

Rituais simplificados e caseiros, conhecimento de ervas, cristais e elementos da natureza fazem parte dessas novas crenças mágicas. A magia e bruxaria voltam a fazer parte da sociedade séculos depois de terem sido rechaçadas e reprimidas, ressurgindo no mundo moderno. A representação da bruxa adquire um outro patamar com a chegada do novo milênio, evoluindo para libertá-la, quase que completamente, da imagem satânica que ainda poderia carregar. Sucessos do cinema e da TV como a saga Harry Potter (2001 - 2011) e The mists of Avalon (2002), já alicerçados pelas obras apresentadas anteriormente, consolidam uma restauração dos conceitos que envolvem a feitiçaria, ambas produções retratando a magia como alheia aos conceitos que a condenam.

Avalon nos mostra Viviane (Anjelica Huston) e sua luta para manter vivas as tradições da ilha encantada em meio ao sufocamento cristão presente no mundo exterior às brumas e a vida de Morgana (Julianna Margules), a futura Senhora de Avalon que abandona sua terra e seu destino para viver longe da terra mágica. A magia, aqui, é nata naqueles nascidos na ilha, devotos da Grande Deusa e vem definhando em um mundo que começa a abandonar as tradições antigas devido à imposição das amarras do Cristianismo, que está em expansão pelos reinos e iniciando seu processo de demonização das culturas a serem suplantadas pela nova fé.

Já Harry Potter tem como característica que o distingue [...]

[...] the absence of any explicit references to religion or demonology; spells are performed without the aid of a higher being, such as Aza(za)el, Hecate, Lilith, or some other deity. The 'dementors' in Potter, who represent a cross between 'demon' and 'dementia', come closest to demons; they suck away will power [...] (BLÉCOURT in DAVIS, 2017, p. 255) 
A magia também é nata nos descendentes dos bruxos, em oposição aos "trouxas"; no entanto, sem qualquer referência religiosa, ela tem a liberdade, assim como em The Craft e Practical Magic, para circular entre as esferas do bem e do mal, dependendo do mago que as usa. Tanto a magia benevolente quando a magia das trevas são acessíveis a todos os bruxos, novamente deixando a responsabilidade do uso a cargo da consciência individual.

Ainda com relação à redenção da imagem tradicional da bruxa má, podemos também citar o filme Maleficent (2014) em que a personagem principal, Malévola (Angelina Jolie), retrata um outro lado do conto de fadas A Bela Adormecida (1812) em que a bela "bruxa má" tem seu papel vingativo e malévolo transformado positivamente para que a ordem se restabeleça. Sem contar o significado positivo que lhe é atribuído como aquela que salva Aurora (Elle Fanning) de seu sono profundo através de um beijo marcado pelo "verdadeiro amor". Nesta cena vemos como a ideia do feminino "construtivo" usurpa o papel do príncipe salvador, aquele - representante masculino - que trará redenção à princesa enclausurada e silenciada.

Podemos dizer que a mesma quebra de paradigma com relação à representação do feminino sombrio está no filme Into the Woods (2014), em que aquela que é retratada como horrenda, vingativa e vilã tem seu aspecto grotesco redefinido positivamente quando a maldição é desfeita mas seus poderes são perdidos. Assim, percebemos que em nossa era contemporânea é possível constatar releituras de um feminino marcadamente sombrio e desfigurado pelo poder patriarcal de nossas sociedades. No entanto, tais releituras podem acabar retornando ao estado mais perverso que, assim como Satanás, perseguem e espreitam a sociedade e a cultura popular que recria tal imaginário.

Setenta e seis anos após The Wizard of $\mathrm{O} z$ nos apresentar a Bruxa do Oeste e iniciar uma tradição imagética da bruxa má, um dos filmes de terror contemporâneos mais populares e polêmicos, The Witch: a New England Folktale (2015), nos apresenta Thomasin (Anya Taylor-Joy), a nova face da bruxa demoníaca. Sua família abandona o vilarejo puritano no qual viviam, justamente por serem considerados rígidos demais pelo resto da sociedade, $\mathrm{e}$ fixam residência às margens de uma floresta, sem que soubessem que aquele era o lugar onde habitavam servas do demônio. O filme, carregado pelo imaginário mais perverso com relação à bruxaria, desde as crenças envolvendo os familiares, animais mágicos que serviam de servos e ajudantes das bruxas, como o coelho, o bode e o corvo, ainda traz as figuras mais clássicas das bruxas.

Primeiramente, a bruxa velha e grotesca que sequestra o bebê da família, matando-o e usando sua carne e sangue em um ritual macabro, esfregando os restos da criança em si mesma e em sua vassoura. Depois, a bruxa mais jovem e com o apelo sexual tão marcante quanto Elvira, seduzindo Caleb (Harvey Scrimshaw), o irmão mais novo de Thomasin e provocando uma das cenas mais fortes do filme, quando o menino retorna a sua casa tempos depois de seu sequestro para, antes da morte, convulsionar junto de delírios orgásticos com visões do Senhor. As bruxas, de The Witch, trazem consigo os piores traços 
relacionados ao Demônio e ao feminino, como a maldade, a capacidade de destruição das famílias, a luxúria e a sexualidade exacerbada para um meio social extremamente conservador e controlador.

Entretanto, talvez a parte mais importante do filme seja, justamente, quando Thomasin conjura Black Phillip, o bode preto da família, a falar com ela, invocando o Demônio e se rendendo após perder toda a sua família morta tragicamente, inclusive com a mãe sendo morta por suas próprias mãos após atacá-la em fúria:

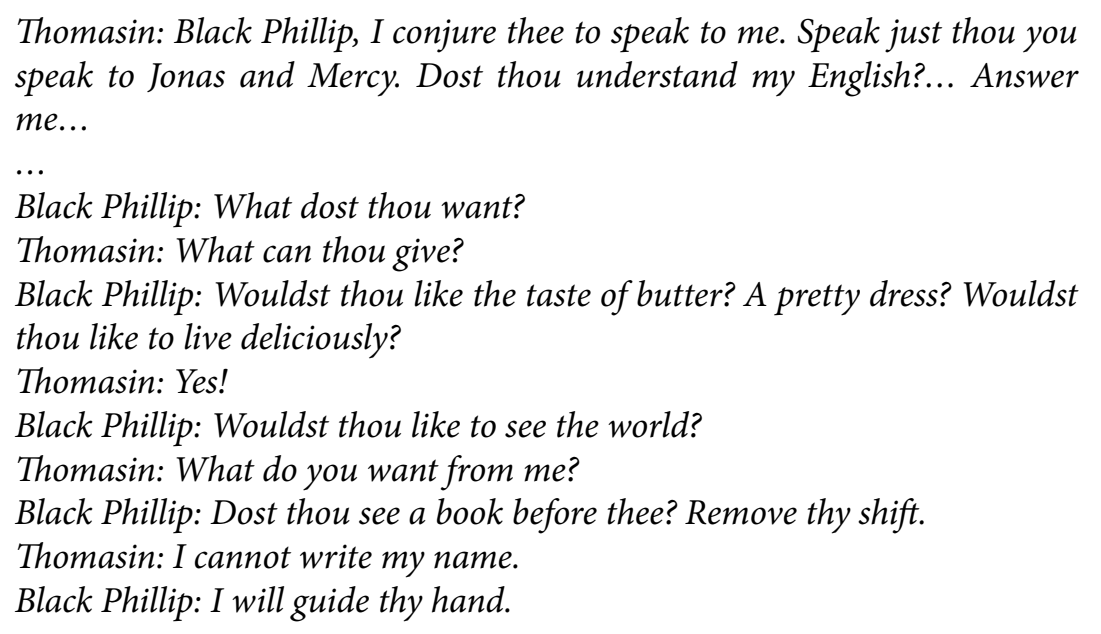

Thomasin se junta ao sabá das bruxas no meio da floresta após assinar o livro do Demônio, todas nuas dançando em êxtase em movimentos descontrolados e animalescos, acompanhadas de seu mestre sob a forma de Black Phillip, até que saem voando, representação essa do imaginário tradicional envolvendo os sabás satânicos (CLARK, 2006, p. 37-60). Mesmo depois de ter perdido tudo o que tinha e de todo o sofrimento causado pelo Diabo, a menina ainda aceita juntarse com o ser perverso em troca dos prazeres que ele pode oferecer. Antes de ser uma representação da bruxaria em seu aspecto mais horrendo, The Witch retrata a bruxa como forma de rebeldia e libertação (CLARK, 2006, p. 130). O Diabo é a maior fonte de maldade e as bruxas suas servas no mundo físico, mas também é aquele que oferece a liberdade em um mundo de amarras e imposições religiosas.

Das culturas mais "primitivas" até o mundo contemporâneo, a magia faz parte da sociedade, independentemente de como ela é vista ou quais são as opiniões sobre ela. Historicamente relacionada com o feminino, a magia se transforma de acordo com a modificação dos contextos sociais, passando de uma forma de conexão com os poderes da natureza, desde o conhecimento a respeito de ervas, ciclos das estações, entendimento dos processos fisiológicos até rituais que buscassem um bem pessoal ou do grupo, como a cura de uma enfermidade ou uma colheita bem-sucedida, até chegar a ser completamente condenada e perseguida em meio a uma histeria religiosa que levou à morte milhares de pessoas, principalmente mulheres por associação com o Diabo dos tempos mais obscuros da Idade Média até os dias de hoje. Embora a sociedade tenha, aparentemente, evoluído tanto em questões sociais quanto religiosas, o 
imaginário referente à bruxaria foi pouco modificado, apesar de haver grandes tentativas de modificação e uma maior abertura para as práticas mágicas como forma de fé. Sem dúvida, tanto o cinema quanto a TV recebem grande parte da responsabilidade sobre como esse imaginário é moldado e como a cultura absorve novas representações de um ícone já tão consolidado.

A imagem da bruxa sofre diversas remodelagens quando observamos as produções audiovisuais que abordam esse tema. Estão presentes figuras grotescas, disformes e caricatas como em The Wizard of $\mathrm{Oz}$ e The Witches, reforçando a feiura como um traço característico da bruxa; no entanto, o que podemos notar é a preferência por ressaltar, mesmo nos casos em que há o aspecto demoníaco ligado a elas, a beleza das feiticeiras, como é o caso de I married a witch e Elvira. Também há a transformação quanto à posição da feiticeira na sociedade. De exclusa e às margens, como a tradição apontava, elas agora fazem parte da comunidade, mesmo que ainda em meio a receios quanto a suas intenções benignas ou malévolas, tendo Practical magic como exemplo.

Por fim, quanto ao eterno dualismo entre bem e mal, não há padrão entre as diversas representações das bruxas por parte do cinema e TV, embora encontremos uma tendência a separar as bruxas boas e más em gêneros diferentes, como a comédia e o terror, ainda não podemos afirmar que haja a dissociação da feiticeira com os dos lados mais sombrios do sobrenatural. Mesmo com exemplos como o da saga Harry Potter, sem qualquer referência religiosa, The mists of Avalon, Practical magic e The Craft, ainda há, em maior peso, pelo menos atributos que podem ser ligados ao Demônio, mesmo que esse, sob a forma de Black Phillip, ofereça a salvação e liberdade das amarras religiosas que, por tanto tempo, condenam não apenas um personagem folclórico, mas todo um gênero associado a ele.

Notas

1. La deidad primordial para nuestros ancestros paleolíticos y neolíticos era femenina, reflejando la soberanía de la maternidad. De hecho, no se ha encontrado imagen alguna de un Dios Padre todo a lo largo del registro prehistórico. Los símbolos e imágenes paleolíticos y neolíticos se arraciman en torno de una Diosa auto generada y sus funciones básicas como Dadora de Vida, Dispensadora de Muerte, y Regeneradora. Este sistema simbólico representa el tiempo cíclico, no lineal, mítico. (GIMBUTAS, M. La Civilización de la Diosa: El mundo de la antigua Europa, 1991, p. 111).

2. La religión de la diosa reflejó un orden social matrístico, matrilineal y endogámico durante la mayor parte de la historia humana temprana. Esto no fue necesariamente un "matriarcado", lo que erróneamente implica el "mando" de las mujeres como imagen refleja de la androcracia. Una tradición matrifocal perduró a través de las sociedades agricultura les primitivas de Europa, Anatolia y el Cercano Oriente, así como de la Creta minoica. En estas culturas el énfasis estaba sobre las tecnologías que nutrían las vidas de la gente, en contraste con el enfoque androcrático sobre la dominación”. (GIMBUTAS, La Civilización..., op. cit., p. 115).

3. De acordo com GIMBUTAS, seu estudo compreende "the period beginning with early agriculture in Europe, some nine to eight thousand years ago. The Neolithic farmers evolved their own cultural patterns in the course of several millennia. Food gathering gave way to food producing and hunting to a settled way of life, but there 
was no corresponding major change in the structure of symbolism, only a gradual incorporation of new forms and the elaboration or transformation of the old. Indeed, what is striking is not the metamorphosis of the symbols over the millennia but rather the continuity from Paleolithic times on. The major aspects of the Goddess of the Neolithic - the birth-giver, portrayed in a naturalistic birth-giving pose; the fertility-giver influencing growth and multiplication, portrayed as a pregnant nude; the life or nourishment-giver and protectress, portrayed as a bird-woman with breasts and protruding buttocks; and the death-wielder as a stiff nude ("bone") - can all be traced back to the period when the first sculptures of bone, ivory, or stone appeared, around 25,000 B.C. and their symbols - vulvas, triangles, breasts, chevrons, zig-zags, meanders, cupmarks - to an even earlier time." (GIMBUTAS, M. The Language of the Goddess. Londres: Thames \& Hudson Ltd., 2001. p. xix).

4. Como nos relata Borges: "Margarida Porete excomungada e sentenciada à morte na fogueira em 1310, por escrever um livro de teologia mística; Joana d’Arc, chefe de guerra de dez mil homens, responsável pela coroação de Carlos VII, encarcerada, acusada de magia e heresia, queimada viva em praça pública, em 1431; Olympe de Gouges, autora da Declaração dos Direitos da Mulher e da Cidadã, levada à guilhotina em 1793 por suas reivindicações; [...] Bruxa, deusa, santa, rainha, guerrilheira, mãe, esposa, concubina, invisível... A mulher escondida, invisível, guardada, reprimida, suspeita, perigosa. É portanto a mesma luta de Margarida, Olympe, Joana, Rosa, Anita, que queriam, como as Marinalvas de hoje, cidadãs anônimas, uma forma mais integral de vida, uma identidade menos mutilada. A história da mulher é também a de seu corpo, da sua sexualidade, de seus amores e sentimentos; da sua loucura, da violência sofrida e da praticada. É a história da família, da religião, do trabalho, da literatura, da educação. Enfim, da diversidade de suas representações e de suas imagens frente à sociedade". BORGES, R., In: BAUER, C. Breve História da Mulher no Mundo Ocidental. São Paulo: Pulsar, 2001.

5. Vale lembrar que pouco se sabe a respeito do paganismo como religião da Europa Ocidental para que se estabeleça uma conexão entre as bruxas de rituais pagãos e os julgamentos da Inquisição. Na Inglaterra, por exemplo, não há evidência da sobrevivência desses cultos após o ano de 1035, parecendo ter desaparecido no continente ainda antes. As bruxas eram consideradas pelo Cristianismo como antagonistas, no entanto, eram condenadas como hereges, não como pagãs (CAVENDISH, 1983, p. 288).

6. Embora o Malleus cite ambos homens e mulheres, ele é dirigido principalmente às bruxas. Seu texto é alimentado pela misoginia, em função da qual são atribuídas a ela características desabonadoras, amealhadas enciclopedicamente e interpretadas como conotações machistas, as mais pejorativas, na primeira parte do livro, para justificar as práticas terríveis prescritas na terceira parte (BYINGTON, 2009, p. 34).

7. Disponível em: https://www.parliament.uk/about/living-heritage/transforming society/private-lives/religion/overview/witchcraft/. Acesso em 02/06/2008.

8. Considerado como um dos pais do cinema, Méliès se utiliza de técnicas de ilusionismo juntamente com as do cinema para a criação de seus filmes, dentre eles Le diable au covent (1900), Le chaudron infernal (1903) e Le diable noir (1905).

9. William Perkins falava para todos os protestantes quando insistia em que, "por Bruxas, nós entendemos não exclusivamente aquelas que matam e atormentam, mas todos os Adivinhos, Encantadores, Bobos, todos os Magos, comumente chamados homens e mulheres ladinhos [...] e no mesmo número nós contamos todas as Bruxas boas, que não fazem mal, mas bem, que não estragam e destroem, mas salvam e libertam". Perkins não era menos representativo da opinião pública inglesa ao dizer também que, dos dois tipos de bruxas, a "boa" era muito pior que a "má" - na verdade, "o Monstro mais horrível e detestável". Isto porque o diabo era diretamente responsável por ambos os conjuntos de ações [...]. O diabo havia 
criado bruxas "boas" ao lado das "más" precisamente para que os enfeitiçados procurassem por elas - e dessa forma, de fato, por ele - para curas, perdendo assim sua integridade espiritual no instante de escaparem de suas aflições materiais. Os feiticeiros e feiticeiras, pensava Perkins, causavam "mil vezes mais dano" que bruxas "más; eles eram 'a mão direita do diabo, pela qual ele se toma e destrói as almas dos homens". Depois do próprio Satã, o mágico da aldeia era "o maior inimigo do nome, da adoração e da glória de Deus que existe no mundo (CLARK, 2006 , p. 585, grifo do autor).

\section{Referências}

BAUER, C. Breve História da Mulher no Mundo Ocidental. São Paulo: Pulsar, 2001.

BLECOURT, Willem de. Witches on screen. In DAVIS, Owen. The Oxford illustrated history of Witchcraft and Magic. Oxford: Oxford University Press, 2017.

CABREIRA, R.H.U. A Condição Feminina em Sociedade: uma releitura de 'A Letra Escarlate' de Nathaniel Hawthorne. São Paulo: Blucher, 2012.

CAVENDISH, Richard. The Black Arts. A concise history of Witchcraft, Demonology, Astrology, Alchemy and other mystical practices throughout the ages. Nova York: Perigee Book, 1983.

CIVITA, R. et. ali., (Dir.) Mistérios Desconhecidos: Bruxas e Bruxarias. Rio de Janeiro: Abril Livros Ltda., 1997.

CLARK, Stuart. Pensando com Demônios. A idéia da bruxaria no princípio da Europa Moderna. São Paulo: EDUSP, 2006.

GIMBUTAS, M. La Civilización de la Diosa: El mundo de la antigua Europa, 1991.

The Language of the Goddess. Londres: Thames \& Hudson Ltd., 2001.

HOWE, Katherine. The Penguin book of Witches. Nova York: Penguin Books, 2014.

MAXWELL-STUART, Peter. Magic in the Ancient world. In DAVIS, Owen. The Oxford illustrated history of Witchcraft and Magic. Oxford: Oxford University Press, 2017.

PAGE, Shopie. Medieval Magic. In DAVIS, Owen. The Oxford illustrated history of Witchcraft and Magic. Oxford: Oxford University Press, 2017.

SHARPE, James. The Demonologists. In DAVIS, Owen. The Oxford illustrated history of Witchcraft and Magic. Oxford: Oxford University Press, 2017.

WALLIS, Robert J. Witchcraft and Magic in the Age of Anthropology. In DAVIS, Owen. The Oxford illustrated history of Witchcraft and Magic. Oxford: Oxford University Press, 2017.

WHITMONT, Edward C. O retorno da Deusa. São Paulo: Summus, 1991.

WITCRAFT ACTS. Disponível em: https://www.parliament.uk/about/livingheritage/transformingsociety/private-lives/religion/overview/witchcraft/. Acesso em $02 / 06 / 2008$.

Filmes:

Bell, book and candle. Direção: Richard Quine. EUA: Julian Blaustein Productions Ltd, 1958 (106 min)

Bewitched. Criador: Sol Saks. EUA: Ashmont Productions, 1966-1972 (256 episódios)

Buffy: the vampire slayer. Criador: Joss Whedon. EUA: $20^{\text {th }}$ Century Fox Television, 1996-2003 (144 episódios)

Elvira: Mistress of the dark. Direção: James Signorelli. EUA: NBC Productions, 1988 (96 min) 
Hocus Pocus. Direção: Kenny Ortega. EUA: Walt Disney Pictures, 1993 (96 min)

I married a witch. Direção: René Clair EUA: René Clair Productions, 1942 (77 min)

Into the woods. Direção: Rob Marshall. EUA: Walt Disney Pictures, 2014 (125 min)

Maleficent. Direção: Robert Strombert. Inglaterra: Walt Disney Pictures, 2014 (97 $\min )$

Practical magic. Direção: Griffin Dunne. EUA: Warner Bros, 1998 (104 min)

Rosemary's baby. Direção: Roman Polanski. EUA: William Castle Productions, 1968 (137 $\mathrm{min})$

Sabrina, the teenage witch. Criadores: Jonathan Schmock e Nell Scovell. EUA: Viacom Productions, 1996-2003 (163 episódios)

The Craft. Direção: Andrew Fleming. EUA: Columbia Pictures Corporation, 1996 (101 min)

The mists of Avalon. Alemanha, República Tcheca e EUA: Constantin Film, 2002 (183 min - 3 episódios)

The witches of Eastwick. Direção: George Miller. EUA: Warner Bros, 1987 (118 min)

The witches. Direção: Nicolas Roeg. Inglaterra: Lorimar Filme Entertainment, 1990 (91 $\mathrm{min})$

The Witch. Direção: Robert Eggers. EUA: Parts and Labor, 2015 (92 min)

The Wizard of Oz. Direção: Victor Fleming. EUA: MGM, 1939 (102 min)

Recebido em: 09/06/2018

Aceito em: 17/08/2018 